\title{
PReS-FINAL-1005: Hypertransaminasemia in systemic juvenile idiopathic arthritis during anti-interleukin 1 treatment
}

\author{
MI Gonzalez Fernandez , R Bou, R Silvia, E Iglesias, J Sánchez, V Torrente, J Antón \\ From 20th Pediatric Rheumatology European Society (PReS) Congress \\ Ljubljana, Slovenia. 25-29 September 2013
}

\section{Introduction}

Systemic juvenile idiopathic arthritis (sJIA) accounts for $10-15 \%$ of JIA patients and is characterized by arthritis with fever, plus rash, generalized lymphadenopathy, hepatosplenomegaly and serositis. It is associated with significant morbidity and may be complicated with macrophagic activation syndrome (MAS). The use of anti-interleukin 1 (IL1) therapy results in dramatic improvement in both the systemic and articular disease.

Elevation of liver enzymes can be seen in sJIA patients because of disease activity, MAS, an infection, hepatotoxicity from pharmacologic treatment or as manifestation of another disease (such as autoimmune hepatitis). Achieving the diagnosis of the hypertransaminasemia in these patients may be difficult for the clinician.

\section{Objectives}

To report 4 patients with sJIA who presented significative and difficult to interpretate hypertransaminasemia while being on IL1 blockers.

To identify and review other sJIA patients in our unit with hypertransaminasemia during anti-IL1 treatment.

\section{Methods}

Medical reports from the sJIA patients treated with IL1 blockers in our unit were reviewed.

\section{Results}

8 patients out of 30 sJIA patients treated with IL1 blockers in our Pediatric Rheumatology Unit since 2004, presented elevation of liver enzymes during anti-IL1 treatment. In 4 of these 8 patients, hypertransaminasemia

\footnotetext{
Paediatric Rheumatology Unit. Pediatrics Department, Hospital Saint Joan de
} Déu, Esplugues, Barcelona, Spain
IL1 inhibitors are effective in sJIA.

Hypertransaminasemia in sJIA patients may result a

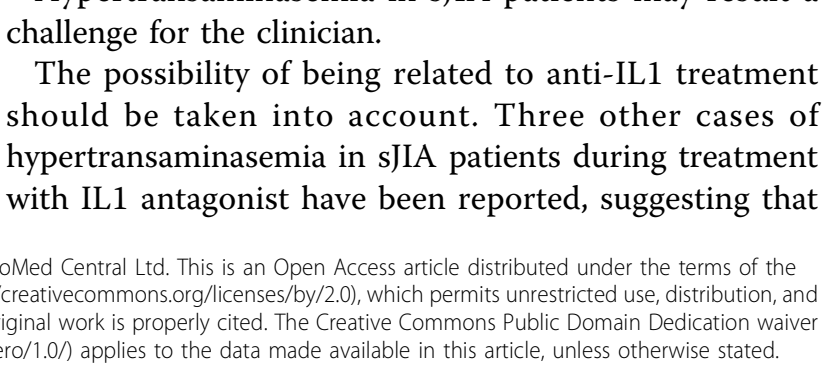

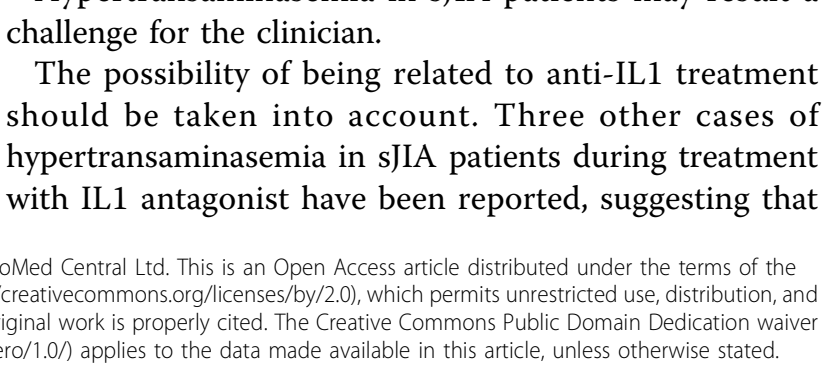

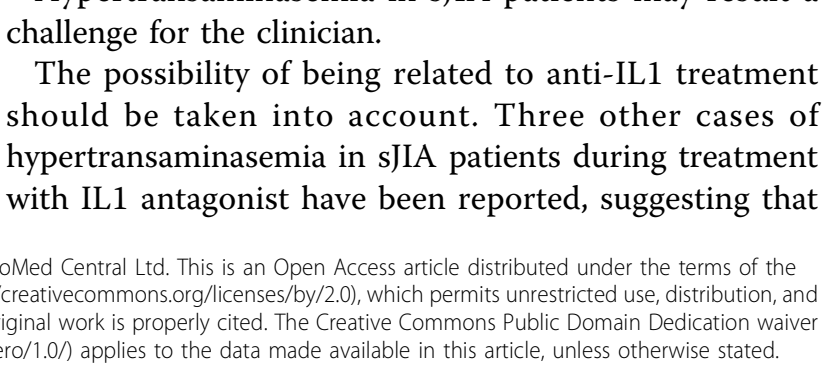

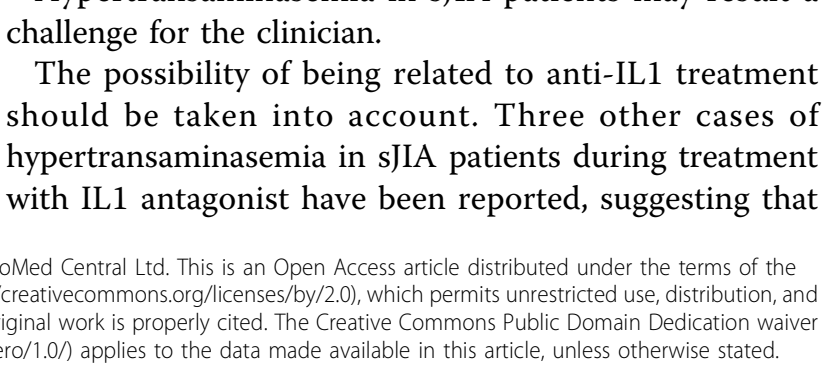

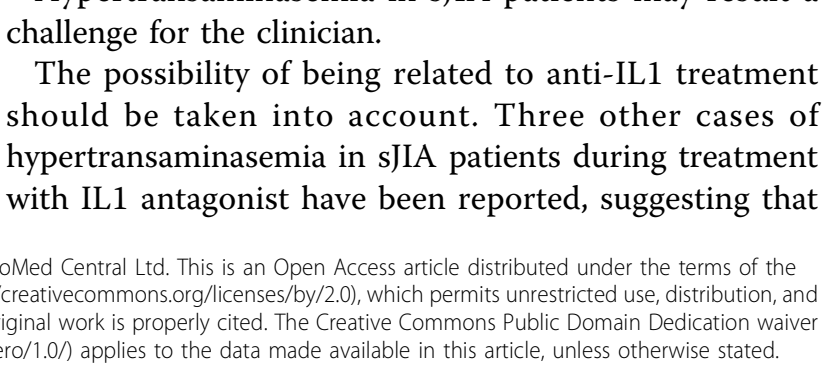

was thought to be related with disease activity or secondinterpretate.

Patient 1 presented elevated transaminases (ALT 2254 disease onset), while prednisone tapering 40 days after MAS. ASMA 1/80. IgG elevation. No evidence of disease flare, MAS, infection, nor other systemic diseases h liver involvement. Anakinra was stopped and liver immune hepatitis. Good response to zathioprine. Anakinra was re-started 4 months later because of a disease flare without subsequent transaminases elevation. hepatitis did not identify a cause. Anakinra was stopped with liver enzymes normalization within 2 months. Patient 4 is a persistent activity patient steroid depenpresented liver enzymes elevations after one dose of canakinumab, while being on anakinra, but also after stopping them; maximum ALT $560 \mathrm{UI} / \mathrm{L}$. Liver biopsy: inflammatory infiltrate without fibrosis. ASMA 1/80. IgG elevation. No evidence of infection, nor other disease with liver involvement. Now she is on anakinra, azathioprine and prednisone with normal liver tests.

\section{Conclusion}


a close monitoring for hepatic toxicity may be indicated when treating with IL1 blockers.

Autoimmune hepatitis is another diagnostic possibility, as shown in two of our patients.

\section{Disclosure of interest}

None declared.

Published: 5 December 2013

doi:10.1186/1546-0096-11-S2-P3

Cite this article as: Gonzalez Fernandez et al:: PReS-FINAL-1005:

Hypertransaminasemia in systemic juvenile idiopathic arthritis during

anti-interleukin 1 treatment. Pediatric Rheumatology 2013 11(Suppl 2):P3.

Submit your next manuscript to BioMed Central and take full advantage of:

- Convenient online submission

- Thorough peer review

- No space constraints or color figure charges

- Immediate publication on acceptance

- Inclusion in PubMed, CAS, Scopus and Google Scholar

- Research which is freely available for redistribution 